\title{
Faust, Freud, machine: encounters and performance
}

\author{
Karamjit S. Gill
}

Published online: 7 March 2013

(C) Springer-Verlag London 2013

As the digital world is increasingly taking hold of our lives, and 'more and more of the value in our lives migrates online', we may be shutting many of the windows of freedom which enable us to seek reconciliation with the world around us, especially freedom from 'exploitation by others' and external forces, as noted by the Editorial in the Observer (2013). Even when digital technology opens new windows of 'freedom' such as 'social networking', it can use the same windows as instruments of control and unfreedom, as illustrated by the surveillance software, Riot, which can track 'people's movements and predicting future behaviour by mining data from social networking websites' (Gallagher 2013). Given the vulnerability and the clouded nature of the digital migration, it may not be long before any of the 'residual digital euphoria' is replaced by 'growing ethical and privacy unease', especially when we are not certain 'what it means to be secure in an online realm'. It could be surmised that just as Taylorism seduced the industrial societies to endure the migration of workers' knowledge and skills more and more to the machine, it seems that digitally inclined policy makers, governments, IT experts, and corporations are wishing and propelling us not only to become adapted to the digital world, but also to fit ourselves into the straight jacket of the data-driven society. The danger of this digital migration is that it may lead not only to the abstraction of the human condition and its contexts, but also to the abstraction of self and identity itself. This abstraction could be a short step towards a distributed digital self, increasingly becoming digitally engaged but socially and emotionally disengaged from contextual living environments. Could it be that this

K. S. Gill ( $₫)$

Professor Emeritus, University of Brighton, Brighton, UK

e-mail: Kgillbton@yahoo.co.uk seeming transition from social to digital engagement is being propagated as a strategic proposition by governments and public organisations in further transforming public services, education, health, welfare, and employment to the digital realm, as if these socially situated services were another form of data management. The consequence of this digitally oriented policy is likely to be the weakening of human presence in the transformative cycle of interaction, mediation, and interlocution, which facilitates the interpretation, dissemination, and communication of contextually relevant and personally and socially responsive services, one of the central ethos of these human services. This weakening of the human presence, or we may call it 'human window', is a step towards closing doors of freedom, a freedom to engage with, influence, and shape public services. It is important to recognise that the design of digital systems, however, technically competent these system may be invariably comes with vulnerabilities, defaults, and brittleness, and their malfunctioning cannot be anticipated. We should, however, take the social and ethical responsibility to at least "change the terms of the debate' on the design, evaluation, and use of digital technologies within diverse user contexts. A system, even a technically competent digital system, is as effective as its weakest component, and any complex technology-mediated system should leave at least some windows open for dealing with uncertain, unforeseen, and unanticipated situations.

Such concerns of the digital migration can be seen as part of the broader debate on issues of the ethics and social responsibility confronting scientists. Rees (2010) gives us an insight into these issues when he says that, 'We must confront widely held anxieties that genetics, brain science and artificial intelligence may "run away" too fast. As citizens, we all need a "feel" for how much confidence can 
be placed in science's claims'. While alerting us to the profound questions of ethics, economics, and social policies concerning the ever pervasive science and technology in our lives, he also asks us to recognise that science also opens doors to engage citizens in making prudent choices of sharing its benefits for humanity in the globalising world. These choices should, however, be facilitated and leveraged by a collaborative engagement between 'scientific citizens' 'attuned to the scope and limit of science' and generally discovering 'the aspirations, needs and preferences of people, and how to meet those needs'. (Rees ibid.) This collaborative leveraging of the choice of science and technology needs to also be of paramount concern regarding ubiquitous technology, including the digital migration of our lives.

In this third issue of the 25th anniversary volume of AI \& Society, our authors discuss some of the social and ethical issues of the pervasiveness of science and technology, closing of windows whilst opening of doors onto the emerging transformation to the digital realm. The authors reflect on the theme, 'What is it to be human in the era of ubiquitous technology?' The reflections and arguments include Could humankind, notably its indefatigable faith in knowledge and technology, find a way out of its predilection towards misusing both? What Faustian paths are we heading along, and which alternative ones are being avoided? Rather than a belief in what technology could do, should we not take a path of what technology should do, and be more collective and more responsive to the actual needs of our era, thereby avoiding the possible catastrophes that the Faustian bargain we have seemingly struck is likely to bring. We wonder whether it is this fear of the Faustian bargain that even contemporary films such as Avatar, Transformers II: Revenge of the Fallen and Iron Man II portray an inherent anxiety towards the cyborg body disavowing of any human/cyborg interaction. Could it be that the cyber space technologies are increasing cultural anxieties about human identity and the notion of self itself, and this hybridity is perceived as yet another bargain with the devil in Faustian terms, especially in contrast to the earlier optimistic vision of Human/Cyborg hybridity of the era of 'The Six Million Dollar Man?' We wonder whether it is to counter this anxiety that we are heading towards the explosion of artefacts into intelligent autonomous agents as surrogates and mediators of the human services, and how we may mitigate the ethical and moral crisis arising out of this over-dependence on artefacts. Is the idea of building empathic agents for creating human-machine immersive collaboration and interaction yet another Faustian seduction? Or is it the cultivation of an empathetic human condition.
From an optimistic perspective, could it be that in the approaching era of ubiquitous technology, the so-called abstract relational strategies would lead to the design of transferable human-computer interfaces just as old technologies such as that of the piano keyboards have historically enabled users to approach other technologies fitted with a similar keyboard interface (e.g., typewriters)? Do the Freudian theories of narcissism, animism, infantile complexes, and ideal ego reflect the changing psychological attitudes towards service and personal robots, and can these attitudes open up wider horizons of human-robot interaction that afford new and fertile grounds for psychoanalytic theorising beyond strictly therapeutic contexts? And do robot enthusiasts envision that robots will become a 'race unto themselves' as they cohabit with the humankind one day? Might the cohabitation with robots act as a catalyst to the co-evolution of human and nonhuman species and the ultimate happiness? Is the information revolution extending the human mind/cognition and extending relationships between the self and the other? Or are we cocooning ourselves in an elaborate info-computational infrastructure of the virtual and increasingly isolating ourselves from the reality of direct experience of the world.

In the midst of the information revolution, humancyborg hybridity, and co-evolution in the cyberspace, we not only need to reflect upon the ensuing ethical and moral dilemmas, but also enter into the learning mode to cope with the collective and uncertain future resulting from this revolution. Moreover, one of the few certainties we may have of our future is that we need to create learning environments which subscribe to knowledge building through social, intergenerational, or intercultural mutual learning. But learning and transformation of human experience to knowledge is rooted in reflection and practice, and herein lies the challenge of recognising the limits of information loaded learning models and tools. The Dialogue Seminar series at the Royal College of Music in Stockholm remind us of the richness of reflective practice and the art of linguistic circumvention in creating mutual learning environments in the image of musical performance as if it were about balancing the tension between lyrics and music of a song.

On this 25 th anniversary occasion, we pay special tribute to our authors, reviewers, readers, and well-wishers the world over, who continue to support AI \& Society through their writings, review comments, critical observations, and constructive suggestions. Special thanks go to our authors of this volume, Douglas Schuler, Simon Bacon, Toyoaki Nishida, Robert Rosenberger, Franco Scalzone and Guglielmo Tamburrini, Min-Sun Kim and Eun-Joo Kim, Gordana 
Dodig-Crnkovic, Bernard Blandin and Bernard Lietaer, Adrian Ratkic, Sven Åberg.

Within its tradition of Symbiotics rooted in the concept of 'human purpose', AI \& Society continues to provide an hospitable forum not only to the openings of science and technology doors, but also to the deep social and ethical concerns of the closing of windows of choice and freedom arising from the ubiquitous technology. A reflection upon the last quarter century of AI \& Society debates draws to our attention that no concept, innovation, or practice is totally independent of context and that all debates, actions, and reflections have important contextual components, including the discussion on the opening of scientific doors and closing of technological windows.

\section{References}

Gallagher R (2013) Software that tracks people on social media created by defence firm, the Guardian, Sunday 10 Feb 2013. http://www.guardian.co.uk/world/2013/feb/10/software-trackssocial-media-defence

Rees M (2010) The Scientific Citizen, Reith Lectures 2010: scientific horizons, the Royal Society, London, 2010. http://www.bbc. co.uk/programmes/b00sk5nc. Accessed 5 Feb 2013

The Observer (2013) Editorial, Web must all take our cyber-security seriously: the tools for safe cyber-living exist. We need to feel they're relevant to us, Observer, 3 Feb 2013. (http://www. guardian.co.uk/commentisfree/2013/feb/03/observer-editorialcyber-hacking-threat). Accessed 3 Feb 2013 